Research Article

\title{
Instability Process Model Test for Bedding Rock Slope with Weak Interlayer under Different Rainfall Conditions
}

\author{
Zhongming $\mathrm{He} \mathbb{D}^{1,2}$ and Baolin Wang ${ }^{2}$ \\ ${ }^{1}$ Key Laboratory of Special Environment Road Engineering of Hunan Province, Changsha University of Science and Technology, \\ Changsha 410114, China \\ ${ }^{2}$ School of Traffic and Transportation Engineering, Changsha University of Science and Technology, Changsha 410114, China
}

Correspondence should be addressed to Zhongming He; hezhongming45@126.com

Received 7 December 2017; Accepted 21 January 2018; Published 15 March 2018

Academic Editor: Xiang Fan

Copyright (c) 2018 Zhongming He and Baolin Wang. This is an open access article distributed under the Creative Commons Attribution License, which permits unrestricted use, distribution, and reproduction in any medium, provided the original work is properly cited.

\begin{abstract}
The instability process of bedding rock slope with weak interlayer may be induced under rainfall infiltration conditions. Due to this, we conducted a research of model test for the instability process, based on the similarity theory. With use of the recent 50 years' rainfall data of Changsha, China, we analyzed the seepage characteristics, mechanical characteristics, and deformation laws of the slope under the conditions of long-time heavy rain and short-time rainstorm, respectively. The test results show that the original seepage characteristics of the slope were changed by the existence of weak interlayer, presented the "double seepage" effect, resulted in the seepage characteristics of rock and soil in the shallow layer and weak interlayer of the slope showed a sickle " $\Gamma$ " distribution, and the adjacent rock layer presented a curve-type " $S$ " distribution. With the increase of rainfall duration, the weak interlayer gradually became muddy and softened, and then the plastic flow zone was formed locally. The stress concentration phenomenon was gradually generated in the weak interlayer due to the influence of the gravitational field of the upper rock mass. The large infiltration of rainwater led to the phenomenon of plastic flow extrusion of the slope at the weak interlayer extrusion. With the further penetration of the tensile cracks in the upper part of the weak interlayer, the slope had a large settlement displacement and gradually formed sliding shear deformation along the weak structural plane. Under the condition of equal rainfall amount, the condition of long-time heavy rain has a greater influence on the stability of the bedding rock slope with weak interlayer than that of short-time rainstorm. The failure form of slope could be divided into four stages: prechange stage, interlayer extrusion stage, slip-pull-fracture stage and plastic flow-shear failure stage.
\end{abstract}

\section{Introduction}

The bedding rock slope refers to the layered rock slope which is consistent with the trend of the whole rock mass and the slope formed by excavation. Such slopes are often at risk of instability due to the large-scale excavation of the original terrain during the formation and disturbance of the initial stress field. When there is a certain degree of strong weathered and weak interlayer in the slope, due to the water softening effect of the weak interlayer, the slope are more prone to instability damage at different degrees whenever the rainy season comes. In recent years, scholars at home and abroad have carried out some researches on the instability mechanism of bedding rock slope. For example, Li et al. [1] studied the dynamic evolution of rock-soil mechanics properties during the development of the landslide based on the typical case of landslide damage along the rocky slope of the Three Gorges reservoir. Shu et al. [2] studied the slope of the rock slope critical inclination and determined the functional relationship between the critical slope of the slip surface and the slope angle, the friction angle of the failure surface, cohesion, and the height of the sliding body. Bedoui et al. [3] aimed at the landslide mechanism of bedding rock slope, and the deep creep of slope landslide is divided into three stages: slope foot to the top of the initial slow deformation stage, slope foot to the middle of the slope surface of the accelerated deformation stage, and rapid deformation of the foot stage. Tiranti et al. [4] analyzed the stability of 
rock slopes in the near-horizontal layers and concluded that rainfall is the most important factor leading to the flat pushtype landslides in such rock slopes. Guzzetti et al. [5] performed in-situ investigation of a large number of Italian bedding rock instability along the slope and a comprehensive analysis of the development of this type of slope instability characteristics and forms of destruction. The above research results provided theoretical support for the analysis of the instability mechanism of bedding rock slope; however, there are still some problems to be perfected [6-9]: (1) when the bedding rock slope contains the weak interlayer, what is the relationship between the instability of the slope and the weak intercalation? (2) Under the conditions of rainfall infiltration, what is the law of the seepage characteristics of this kind of slope and what kind of rainfall condition has the most influence on the rock slope with the weak interlayer. (3) Before and after rainfall, what happens to the mechanical properties of the rock slope and the weak interlayer, and how this change will affect the stability of the slope.

Therefore, this paper relied on the bedding rock slope with weak interlayer along the left side of the Beijing-Zhuhai Expressway (Changsha-Zhuzhou section). Based on the theory of similar materials and combined with the indoor rainfall-spraying technique, model tests on the instability process of bedding rock slope with weak interlayer under different rainfall conditions were carried out, and the change law of volumetric water content, sliding thrust, and settlement of this type of slope under rainfall infiltration was analyzed. According to the test results, the most unfavorable rainfall conditions affecting slope stability were discussed, and the failure modes of bedding rock slope with weak interlayer under rainfall infiltration were proposed, which provided theoretical guidance for engineering practice.

\section{Relying on the Slope Overview}

The left side of the Beijing-Zhuhai Expressway (ChangshaZhuzhou section) is a high-cut rock slope. Due to the restriction of the terrain and the route, the slope was generally excavated at a ratio of $1: 1$, and the first and second grade slopes were high $10 \mathrm{~m}$. The slope of the third grade was high $8 \mathrm{~m}$. Through the samples of on-site core drilling, it was found that the $3 \mathrm{~m}$ below the surface of the slope was strongly weathered shale and residual soil, and the lower $3 \mathrm{~m}$ was medium weathered shale, and the strike of the rock layer is basically the same as that of the excavated slope, which was the bedding rock slope. Due to the influence of geological structure and environmental factors, some rock strata in the second-level slope were relatively broken, fractures and joints were well developed, and were interbedded with the adjacent shale thin layers to form a strong weathering weak interlayer with a thickness of about $3 \mathrm{~m}$. The strong weathering weak interlayer was exposed on the surface of the second slope. When the rainy season comes, the rainwater infiltrates into the weak interlayer quickly to form a muddy sliding surface, which affected the overall stability of the slope. Therefore, this paper selected the rock-cut slopes with weak interlayer as the research object and carried out the model test of bedding rock slope with weak interlayer under different rainfall conditions. Influenced

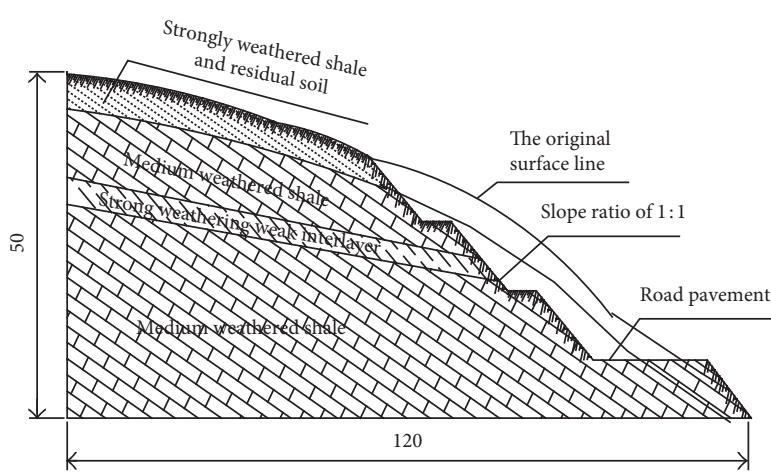

Figure 1: Engineering slope generalized model.

by the factors such as the model and rainfall, only the slopes of $30 \mathrm{~m}$ in length, $60 \mathrm{~m}$ in width, and $40 \mathrm{~m}$ in height were selected in this paper. The generalized model is shown in Figure 1.

\section{Model Test Program}

3.1. Design Rainfall Conditions. In order to draw up the most reasonable rainfall condition, relied on the slope engineering in Changsha area of Hunan Province, the rainfall data of Changsha area in recent 50 years are analyzed (Table 1) [10]. As it can be seen from Table 1 , the average annual rainfall days in Changsha area of Hunan Province reached 1/3 of the whole year, the average daily rainfall intensity was above $10 \mathrm{~mm}$, and extreme rainfall situations also occurred from time to time.

The difference of rainfall conditions are mainly the difference of rainfall intensity and rainfall duration [11-13]. In order to analyze the influence of rainfall conditions on the bedding rock slope with weak interlayer under the rainfall infiltration condition, according to the rainfall data in recent 50 years in Changsha area, two rainfall grades heavy rain and rainstorm were formulated. At the same time, the total rainfall was set to $60 \mathrm{~mm}$. The rainfall intensity of heavy rain condition was $4.63 \times 10^{-4} \mathrm{~mm} / \mathrm{s}$, the rainfall duration was $36 \mathrm{~h}$, and the rainfall intensity of rainstorm condition was $9.26 \times 10^{-4} \mathrm{~mm} / \mathrm{s}$, and the rainfall duration was $24 \mathrm{~h}$. Specific rainfall conditions are shown in Table 2.

3.2. Determine the Similarity Ratio. In this paper, an engineering example was given. The geometric dimension of the bedding rock slope with weak interlayer on the left side of the Beijing-Zhuhai Expressway (Changsha-Zhuzhou section) is large. The model test of $1: 1$ is carried out in the laboratory to simulate the slope instability process: not only the volume of labor is large but also unrealistic. For a more realistic model test of bedding rock slope with weak interlayer under different rainfall conditions, the size of the prototype slope needs to be scaled reasonably. Reference to the relevant literature $[14,15]$ and the model test die size, the geometric similarity ratio of the slope was selected as 1:50. Considering the change of sliding thrust before and after rainfall infiltration caused by the specific weight of rock, selected specific weight ratio $c_{\gamma}$ was $1: 1$, the internal friction angle $c_{\varphi}$ was $1: 1$, and the cohesion $c_{c}$ was $1: 50$. The other similitude ratio of related rock mechanics parameters 
TABLE 1: Rainfall data in Changsha in recent 50 years.

\begin{tabular}{|c|c|c|c|c|c|}
\hline Years & $1961 \sim 1970$ & $1971 \sim 1980$ & $1981 \sim 1990$ & $1991 \sim 2000$ & $2001 \sim 2010$ \\
\hline Average annual rainfall days & 140 & 132.8 & 132.6 & 139.5 & 129.3 \\
\hline Average annual rainfall frequency & 0.383 & 0.364 & 0.363 & 0.382 & 0.354 \\
\hline Average annual rainfall (mm) & 1434.86 & 1343.17 & 1361.36 & 1589.53 & 1347.25 \\
\hline Average daily rainfall intensity $(\mathrm{mm})$ & 10.25 & 10.11 & 10.27 & 11.39 & 10.41 \\
\hline Extremely average rainfall $(\mathrm{mm})$ & 3056.8 & 2304.6 & 1612.5 & 590.3 & 1795.25 \\
\hline Extreme rainfall days & 40 & 32 & 22 & 10 & 32 \\
\hline Extreme rainfall intensity $(\mathrm{mm})$ & 76.42 & 72.01 & 73.29 & 59.03 & 56.10 \\
\hline
\end{tabular}

Notes. Average daily rainfall intensity = average annual rainfall/average annual rainfall days; extreme rainfall intensity = extremely average rainfall/extreme rainfall days.

TABLE 2: Rainfall conditions.

\begin{tabular}{lcc}
\hline & Rainfall condition 1 & Rainfall condition 2 \\
\hline Rainfall grade & Heavy rain & Rainstorm \\
Rainfall intensity $(\mathrm{mm} / \mathrm{s})$ & $4.63 \times 10^{-4}$ & $9.26 \times 10^{-4}$ \\
Rainfall duration $(\mathrm{h})$ & 36 & 24 \\
Total rainfall $(\mathrm{mm})$ & 60 & 60 \\
\hline
\end{tabular}

TABLE 3: Similitude ratio of geotechnical mechanical parameters.

\begin{tabular}{lccccccccc}
\hline & $\begin{array}{c}\text { Geometric } \\
\text { dimensions } C_{l}\end{array}$ & $\begin{array}{c}\text { Specific } \\
\text { weight } C_{\gamma}\end{array}$ & $\begin{array}{c}\text { Internal } \\
\text { friction angle } \\
C_{\varphi}\end{array}$ & $\begin{array}{c}\text { Cohesion } \\
C_{c}\end{array}$ & $\begin{array}{c}\text { Elastic } \\
\text { modulus } \\
C_{E}\end{array}$ & $\begin{array}{c}\text { Displacement } \\
C_{\delta}\end{array}$ & $\begin{array}{c}\text { Shearing } \\
\text { stress } C_{\tau}\end{array}$ & $\begin{array}{c}\text { Poisson's } \\
\text { ratio } C_{\mu}\end{array}$ & $\begin{array}{c}\text { Permeability } \\
\text { coefficient } C_{k}\end{array}$ \\
\hline $\begin{array}{l}\text { Similitude } \\
\text { ratio }\end{array}$ & 50 & 1 & 1 & 50 & 50 & 50 & 50 & 1 & $\sqrt{50}$ \\
\hline
\end{tabular}

according to the theory of similarity relations was obtained, as shown in Table 3.

3.3. Proportioning of Similar Materials. In order to carry out the model test on the bedding rock slope with weak interlayer on the left side of the Beijing-Zhuhai Expressway (Changsha-Zhuzhou section), the geotechnical parameters of each structural layer of the prototype slope must be determined. Therefore, the prototype slope was sampled on site, and then the geotechnical parameters of each structural layer of the slope were determined through laboratory correlation experiments. Among them, the permeability coefficient of strongly weathered shale and residual soil layer, strong weathered weak interlayer layer, and medium weathered shale layer was determined by the indoor variable head penetration test, which was $1.21 \times 10^{-6} \mathrm{~cm} \cdot \mathrm{s}^{-1}, 3.26 \times 10^{-4} \mathrm{~cm} \cdot \mathrm{s}^{-1}$, and $6.53 \times 10^{-7} \mathrm{~cm} \cdot \mathrm{s}^{-1}$, respectively. Cohesion and internal friction angle were determined by the indoor large-scale direct shear test. Cohesion was $256 \mathrm{MPa}, 56 \mathrm{MPa}$, and $452 \mathrm{MPa}$, and internal friction angle was: $32^{\circ}, 16^{\circ}$, and $52^{\circ}$. Other rock and soil mechanical parameters are selected according to the previous experimental experience and the relevant literature [16-18] data. Finally, according to the similarity ratio deduced from the similarity theory, the rock and soil mechanics parameters of similar materials were calculated, and the results are shown in Table 4.

The ratio of similar materials means that, in order to make similar materials meet the requirements of some strength parameters, the proportion of raw materials should be combined according to a certain gradation [19]. Due to the diversity and complexity of the influencing factors of similar materials, it is not easy to fully meet the requirements of various geotechnical mechanical parameters. It is necessary to make ideal similar materials according to the research results of scholars at home and abroad and a large number of orthogonal experiments. Therefore, this paper based on previous research results $[20,21]$, selected barite powder, quartz sand as filler, cement, gypsum as cementing material, water, and clay as ingredients. In order to accord with the requirements of geotechnical parameters of each structural layer of the model slope in Table 4, raw materials of similar materials are formulated according to a certain proportion. Among them, the strong weathered shale and residual soil layer was prepared according to barite powder: quartz sand: clay: cement: gypsum : water $=60: 22$ : $31: 3: 2: 13$, the strong weathered weak interlayer layer was prepared by quartz sand: clay: water $=2: 8: 3$, and the medium weathered shale layer was formulated on the basis of barite powder : quartz sand : cement : gypsum $:$ water $=55: 31: 8: 1.5: 6$. The required raw materials formulated are shown in Figure 2.

3.4. Model Test Program. The model test was carried out indoors. First of all, the prepared similar materials were sequentially filled into the slope mold, standing for $48 \mathrm{~h}$, and then the grouting material was divided into three stages according to the slope ratio of $1: 1$, excavation was completed and then allowed to rest for 72 hours, so that the slope reaches stable state. Secondly, for the sake of simulating the rainfall on the slope, the rainfall-spraying device was installed on the top of the mold and then adjusted the rainfall intensity and rainfall duration according to the two rainfall 
TABLE 4: Prototype and model slope of rock and soil mechanics parameters.

\begin{tabular}{|c|c|c|c|c|c|c|c|}
\hline & Lithology of structural layer & $\begin{array}{l}\text { Specific weight } \\
\left(\mathrm{kN} \cdot \mathrm{m}^{-3}\right)\end{array}$ & $\begin{array}{c}\text { Internal } \\
\text { friction angle } \\
\left({ }^{\circ}\right)\end{array}$ & $\begin{array}{l}\text { Cohesion } \\
c(\mathrm{kPa})\end{array}$ & $\begin{array}{c}\text { Elastic } \\
\text { modulus } E \\
(\mathrm{MPa})\end{array}$ & $\begin{array}{l}\text { Poisson's } \\
\text { ratio } \mu\end{array}$ & $\begin{array}{c}\text { Permeability } \\
\text { coefficient } K \\
\left(\mathrm{~cm} \cdot \mathrm{s}^{-1}\right)\end{array}$ \\
\hline \multirow{3}{*}{$\begin{array}{l}\text { Prototype } \\
\text { slope }\end{array}$} & $\begin{array}{l}\text { Strongly weathered shale } \\
\text { and residual soil layer }\end{array}$ & 26 & 32 & 256 & 2700 & 0.29 & $1.21 \times 10^{-6}$ \\
\hline & $\begin{array}{l}\text { Strong weathering weak } \\
\text { interlayer }\end{array}$ & 17 & 16 & 56 & 900 & 0.42 & $3.26 \times 10^{-4}$ \\
\hline & $\begin{array}{c}\text { Medium weathered shale } \\
\text { layer }\end{array}$ & 32 & 52 & 452 & 6300 & 0.18 & $6.53 \times 10^{-7}$ \\
\hline \multirow{3}{*}{$\begin{array}{l}\text { Model } \\
\text { slope }\end{array}$} & $\begin{array}{l}\text { Strongly weathered shale } \\
\text { and residual soil layer }\end{array}$ & $26(25)$ & $32(31)$ & $5(7)$ & $54(55)$ & 0.29 & \multirow{3}{*}{$\begin{array}{c}1.71 \times 10^{-7} \\
\left(1.75 \times 10^{-7}\right) \\
4.61 \times 10^{-5} \\
\left(4.68 \times 10^{-7}\right) \\
9.23 \times 10^{-8} \\
\left(9.30 \times 10^{-7}\right)\end{array}$} \\
\hline & $\begin{array}{l}\text { Strong weathering weak } \\
\text { interlayer }\end{array}$ & $17(18)$ & $16(18)$ & $1(1)$ & $18(17)$ & 0.42 & \\
\hline & $\begin{array}{c}\text { Medium weathered shale } \\
\text { layer }\end{array}$ & $32(32)$ & $52(50)$ & $9(12)$ & $1260(1256)$ & 0.18 & \\
\hline
\end{tabular}

Note. Value of the test results of similar materials.

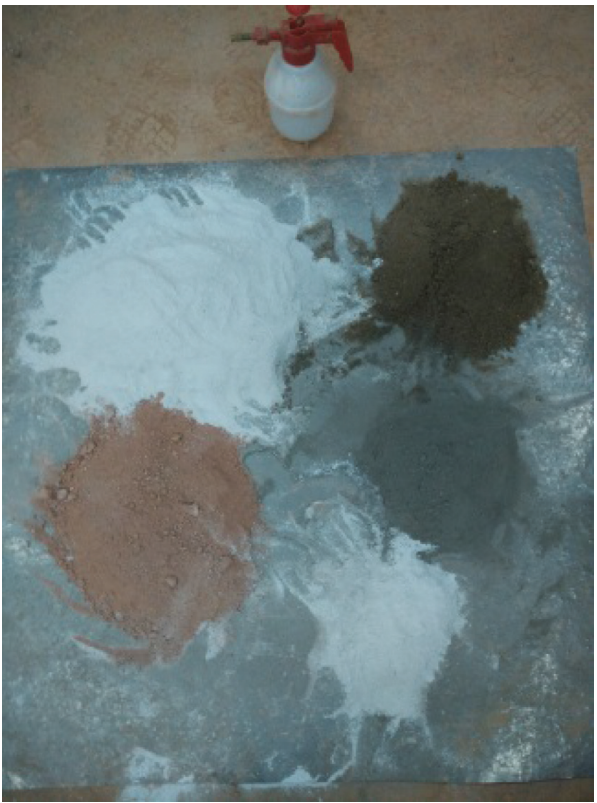

Figure 2: Test raw materials.

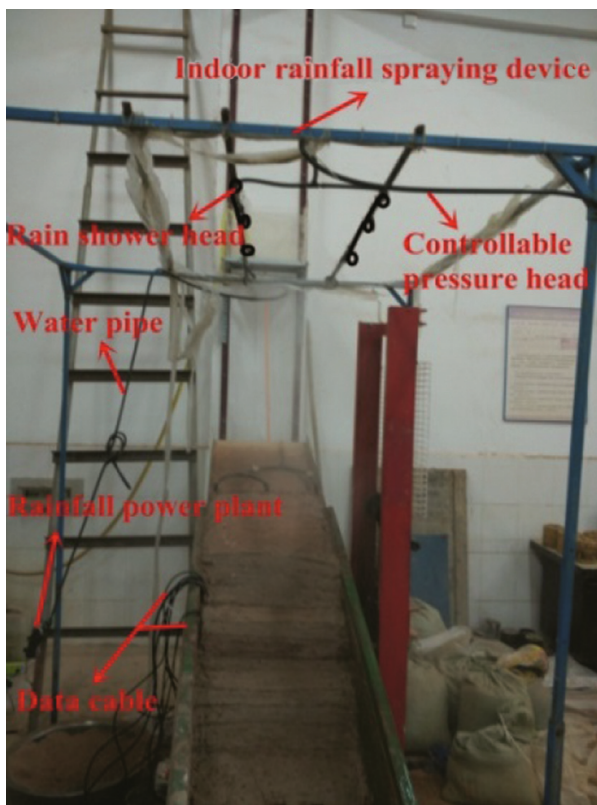

FIgURE 3: Indoor rainfall model test system. conditions shown in Table 2. Thirdly, after the rainfall is over, the model was left standing for a period of time to monitor the deformation of the slope model after rain. The model test system is shown in Figure 3.

In order to focus on the inherent relationship between the strong weathered weak interlayer layer and the slope instability, this paper measures the volumetric water content, sliding thrust, and settlement before and after rainfall infiltration. The monitoring points $P 1, P 2, P 3, P 4, P 5$, and $P 6$ of the volumetric water content were equidistantly arranged at the below of the slope top with an interval of $4 \mathrm{~cm}$. Among them, $P 1 \sim P 3$ were located above the weathered weak interlayer, $P 4$ was located in the interlayer, and $P 5$ and $P 6$ were located below the interlayer. The earth pressure box was buried at the weak interlayer of the second-stage slope, containing three monitoring points $F 1, F 2$, and $F 3$, and the three monitoring points were separated by $3 \mathrm{~cm}$, respectively. Displacement monitoring points $S 1, S 2$, and
S3 were located at the outcrop of the second-stage weak interlayer, with $S 1$ above the interlayer, $S 2$ within the interlayer, S3 below the interlayer, and $4 \mathrm{~cm}$ intervals between the 3 monitoring sites. Test equipment and monitoring points laid are shown in Figures 4 and 5.

\section{Analysis of Test Results}

4.1. Variation of Slope Seepage Characteristics. In order to analyze the seepage characteristics of rainfall infiltration in the bedding rock slope with weak interlayer, the monitoring points $P 1 \sim P 6$ of volumetric water content in the slope were monitored, respectively, under two kinds of rainfall conditions, heavy rain and rainstorm. The monitoring results are shown in Figures 6 and 7. As shown in Figures 6 and 7, we found that the uplift time of the volume water content monitoring point $P 1 \sim P 6$ in the slope was $P 4>P 1>P 2>P 5>P 3>P 6$, but the 


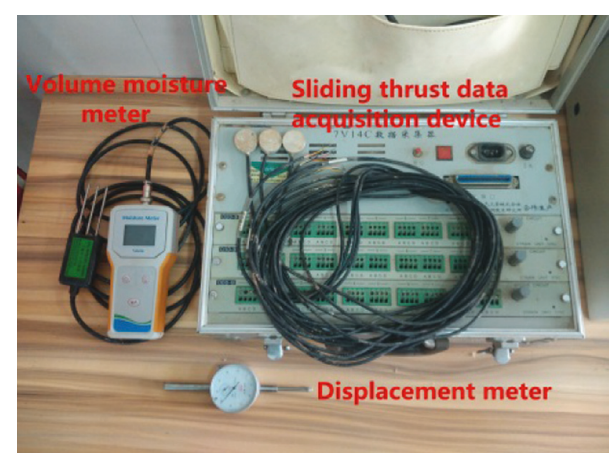

Figure 4: Test instrument.

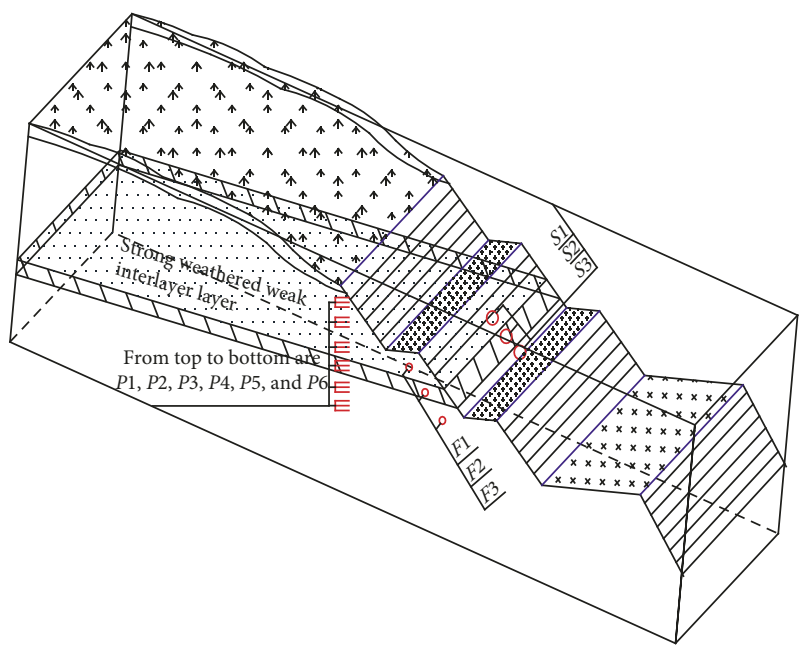

FIgURE 5: Layout of monitoring points. $P$ is the monitoring point of volume water content, $F$ is the sliding thrust monitoring point, and $S$ is the displacement monitoring point.

uplift rate was $P 4>P 1>P 2>P 3>P 5>P 6$. With the increase of rainfall duration, the volumetric water content over $P 1, P 2$, and $P 4$ showed a sickle " $\Gamma$ " distribution, while $P 3, P 5$, and $P 6$ showed a curve-type " $S$ " distribution. At the stage of rain stop, with the dissipation of rainwater, the rate of decrease of volumetric water content at monitoring points was $P 1>P 2>P 3>P 6>P 5>P 4$. This phenomenon may be induced by the following reasons:

(1) The seepage of the slope surface continues to flow to the slope under the effect of the gravitational field, and the seepage characteristics and the buried depth meet the monotonic decreasing function relationship.

(2) In addition to the part of the rainwater infiltrating into the weak interbed that flowed downwards due to the gravitational field, the other part would flow upward due to capillary action, leading to the inverse function relationship between the seepage characteristics of this part of rainwater and the depth of the embedded layer.

Therefore, the original seepage characteristics in the slope were broken due to the presence of weak intercalation, which led to the distribution of volumetric water content that no

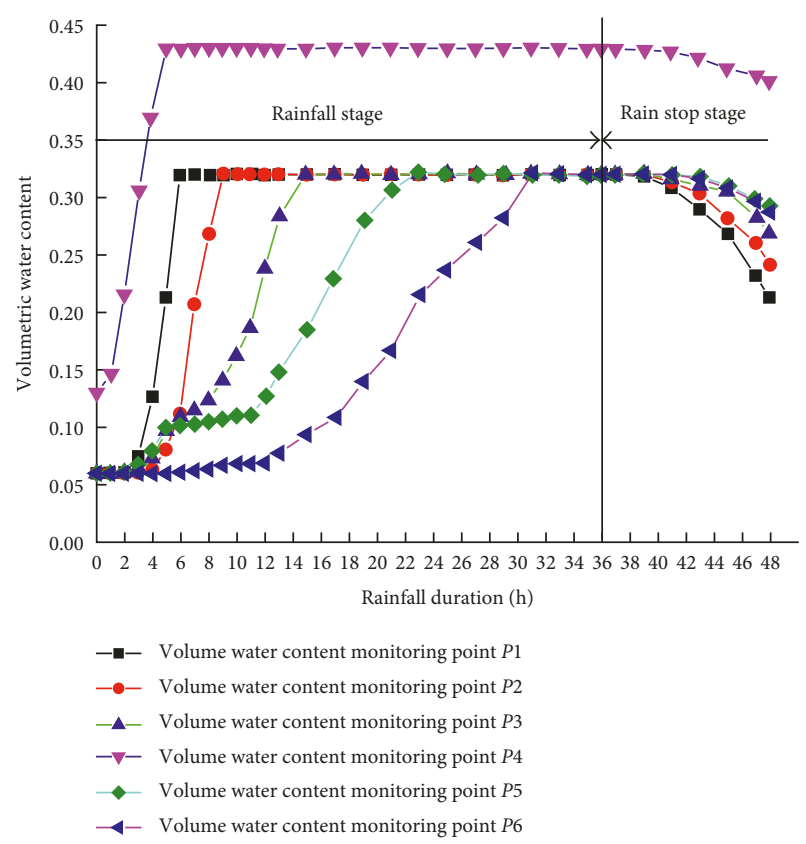

FIGURE 6: Variation law of volumetric water content with rainfall duration under long-time heavy rain.

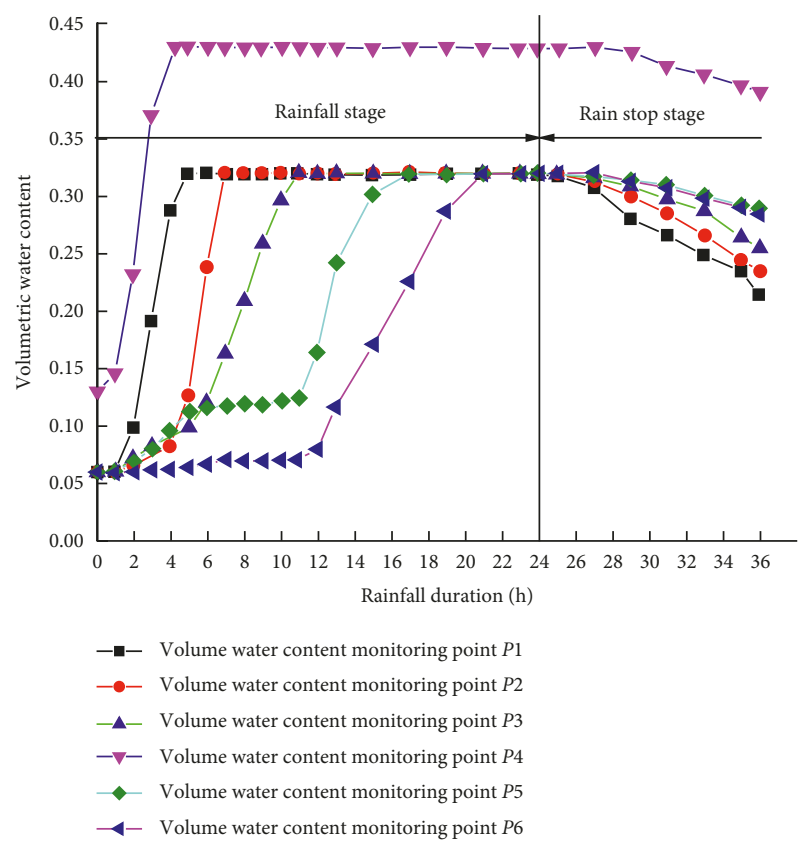

FIGURE 7: Variation law of volumetric water content under shorttime rainstorm.

longer met the monotonic decreasing function as the depth of the buried depth increases. The seepage characteristics of rock and soil in the shallow layer and weak interlayer of the slope showed a sickle " $\Gamma$ " distribution, and the adjacent rock layer presented a curve-type "S" distribution. In addition, the high permeability of the weak interlayer creates a new seepage path for rainwater infiltration into the slope, which makes rainwater not only infiltrate from the slope surface but also 
penetrate into the interior of the slope through the weak interlayer, showing a "double seepage" effect.

4.2. Evolution Law of Sliding Thrust ahead of Slope. For the bedding rock slope with weak interlayer, the intervention of rainwater will muddy the weak layer and further reduce the shear strength of the layer, leading to the instability of the slope. In order to analyze the evolution of the mechanical properties of the slope under rainfall infiltration, the sliding thrust of the weak interlayer and the adjacent structural layer in the model slope was monitored (as shown in Figures 8 and 9). Under the condition of long-time heavy rain, the sliding thrust of three monitoring points $F 1 \sim F 3$ gradually increased and the monitoring point $F 2$ in the weak interlayer increased most rapidly. During the rainfall period of $28 \sim 34 \mathrm{~h}$, the slip thrust at monitoring point $F 2$ rapidly increased from $13 \mathrm{MPa}$ to $35 \mathrm{MPa}$ and then stabilized at $35 \mathrm{MPa}$, The sliding thrust of the monitoring point $F 1$ was lower than $F 2$ at $28 \mathrm{~h}$, which was stable at about $15 \mathrm{MPa}$, and the minimum change of F3 was $7 \mathrm{MPa}$ at the monitoring point. Under the condition of shorttime rainstorm, the monitoring point F2 did not show obvious phenomenon of rapid increase, the maximum sliding thrust stable at $19 \mathrm{MPa}$ or so, monitoring point $F 1$ maximum sliding thrust stable at $9 \mathrm{MPa}$ or so, and the monitoring point F3 was stable at $5 \mathrm{MPa}$, which was obviously lower than the sliding thrust under long-time heavy rain condition.

The reason for this phenomenon is that, with the "double seepage" effect of rainwater on the slope surface and the weak interlayer, the bulk density of the rock mass in the upper section of the interlayer gradually increased and the weak interlayer gradually becomes muddy and softens. As a result, the slope tends to slip along the weak structure surface, resulting in the sliding thrust of the interlayer, and the adjacent structure layer increased gradually. Among them, the sliding thrust increased fastest in the weak interlayer. When the shear strength in the interlayer decreased to a certain extent, the gravitational field in the upper rock mass will form stress concentration in the inner layer of the muddied layer, so that the sliding thrust of the interlayer increased rapidly, which aggravated the tendency of the slope slip, and formed the shear deformation along the weak structural plane, resulting in the instability of the slope.

4.3. Deformation Law of Slope Settlement. In the bedding rock slope with weak interlayer, rainfall infiltration will muddy the interlayer and form the plastic flow zone, reducing the strength of the interlayer and leading to large deformation and failure of the slope. In order to analyze the deformation and failure of this type of slope under the conditions of rainfall infiltration, the settlement displacements at slope monitoring points $S 1 \sim S 3$ were monitored (as shown in Figures 10 and 11).

As can be seen from Figures 10 and 11, with the continuous infiltration of rainfall, the subsidence displacement produced in the slope monitoring point gradually increased, and the increasing rate was in the order of $S 2>S 1>S 3$. Under the long-time heavy rain condition, the maximum settlement deformation of the monitoring point $S 2$ in the

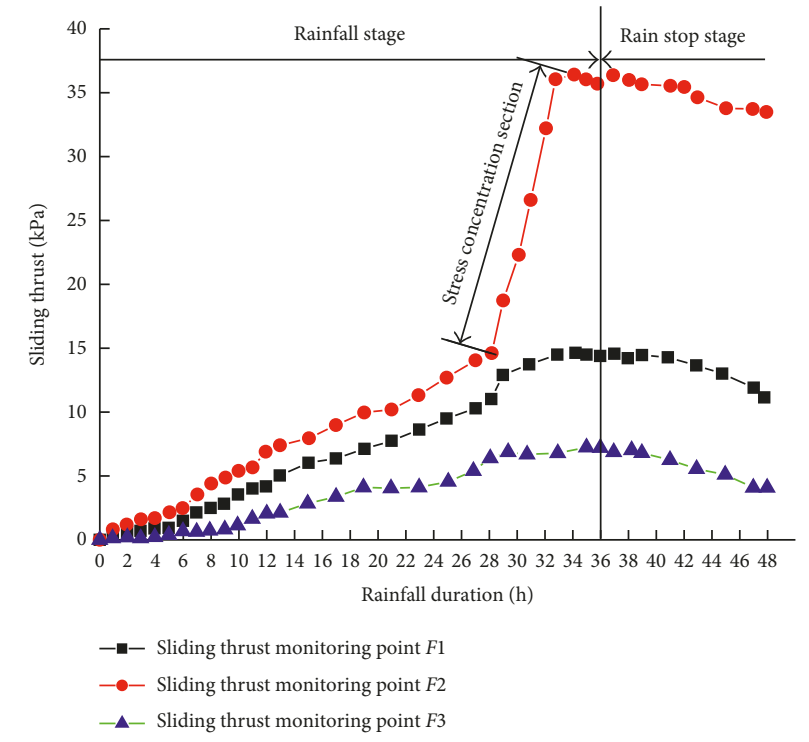

FIGURE 8: Variation law of sliding thrust under long-time heavy rain.

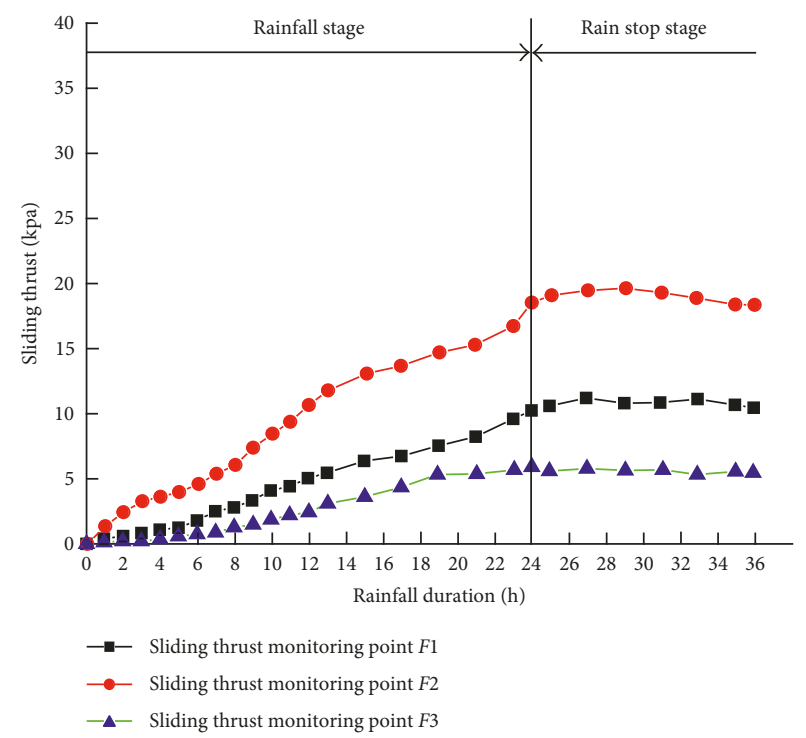

FIgURE 9: Variation law of sliding thrust under short-time rainstorm.

interlayer reached $23 \mathrm{~mm}$, and the maximum settlement deformation of the monitoring point $S 2$ was only $17 \mathrm{~mm}$ under the short-time rainstorm condition. Obviously, the settlement and deformation under long-time heavy rain were obviously larger than those of short-time rainstorm. Under the condition of long-time heavy rain, the change curve of settlement and displacement of the monitoring point $S 2$ in the interlayer shows obvious 4-stage deformation:

4.3.1. Prechange Stage. In the early stage of rainfall, rainwater seeped through the two paths at the slope surface and 


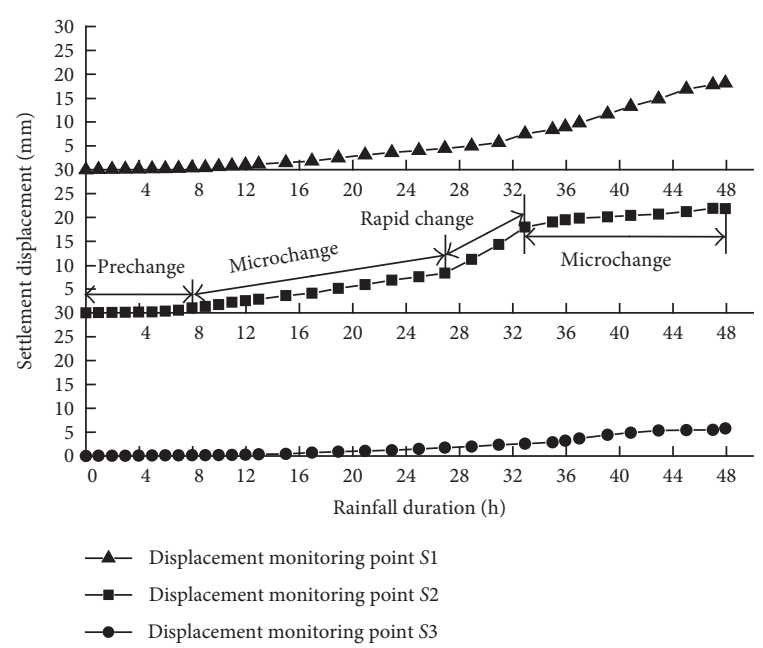

Figure 10: Variation law of settlement displacement under longtime heavy rain.

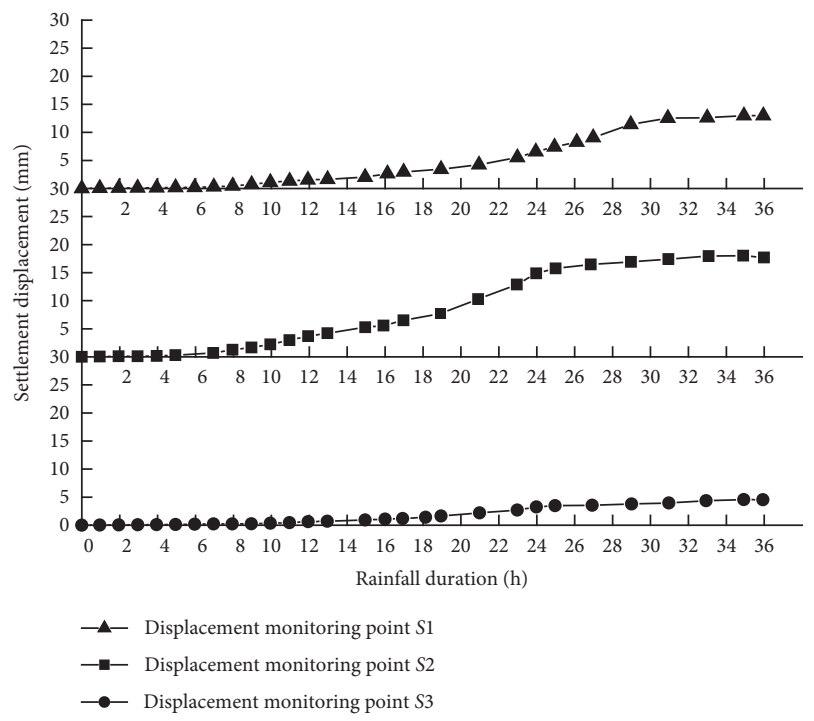

FIGURE 11: Variation law of settlement displacement under shorttime rainstorm.

the weak interlayer, gradually wetted the interlayer, and the weight of the upper part of the interlayer slowly increased.

4.3.2. Microchange Stage. The continuous infiltration of rainwater in the interlayer led to the further decrease of the interlayer strength and gradually formed the plastic flow zone. Due to the self-weight stress of the upper rock mass, some crushing and sinking deformation occurred in the interlayer.

4.3.3. Rapid Change Stage. With the infiltration of rainwater, the gravitational field of the upper rock mass in the interlayer was also increased while the interlayer was muddied, resulting in stress concentration in the plastic flow region of the interlayer and a significant increase of the sliding thrust. At this time, the slope produced plastic flowtensile deformation and failure, and the settlement displacement increased significantly.
4.3.4. Microchange Stage. After the slope instability occurred at the interlayer, the tendency of increase of settlement displacement was obviously reduced. With the gradual dissipation of rainfall, the settlement displacement of the slope was stabilized to a certain value after the rain stops.

\section{Instability Forms}

According to the test results of long-time heavy rain (Figures 6, 8, and 10), the instability forms of this kind of slope can be divided into 4 stages: prechange stage, interlayer extrusion stage, slippull-fracture stage, and plastic flow-shear failure stage.

5.1. Prechange Stage. Due to the "double seepage" effect of rainwater, the volumetric water content in the slope surface and interlayer gradually increased and the sliding thrust slowly increased at the initial stage of rainfall without breaking the original stable condition of the slope; therefore, it did not produce certain deformation.

5.2. Interlayer Extrusion Stage. Rain infiltration in the interlayer continued to make the interlayer gradually muddy and softened, forming a local plastic flow zone; the intensity was significantly reduced. Affected by the gravitational field of the upper rock mass, the interlayer was gradually squeezed to produce certain crushing and settlement deformation, resulting in the continuous increase of the internal sliding thrust and the gradual slip trend of the slope.

5.3. Slip-Pull-Fracture Stage. The cracks in the upper part of the interlayer were well developed and some tensile stress appeared, which had the development trend of going through the upper part of the rock mass from bottom to top. Under the action of gravitational field, the interlayer was further squeezed and stress concentration occurred in the interlayer, which caused the sliding thrust to increase rapidly and produced larger settlement deformation.

5.4. Plastic Flow-Shear Failure Stage. With the infiltration of a large amount of rainwater, the strength of the weak interlayer was further reduced, and the tension cracks generated in the upper rock mass of the interlayer further expanded. The phenomenon of plastic flow extrusion occurred at the interlayer extrusion, and the shear deformation along the weak structural surface was gradually formed, which eventually led to the instability of the slope.

\section{Conclusion}

In this paper, based on the bedding rock slope with the weak interlayer on the left side of Beijing-Zhuhai Expressway (Changsha-Zhuzhou section), the model test of bedding rock slope with weak interlayer under rainfall infiltration was carried out. According to the result, we found the following results:

(1) The test results show that the original seepage characteristics of the slope would be changed by the 
existence of the weak interlayer under rainfall infiltration conditions, presented the "double seepage" effect, and opened up a new seepage path for rainwater infiltration. The seepage characteristics of rock and soil in the shallow layer and weak interlayer of the slope showed a sickle " $\Gamma$ " distribution, and the adjacent rock layer presented a curve-type "S" distribution.

(2) As the rainfall infiltration continued, the weak interlayer gradually became muddy and softened, forming a plastic flow zone locally. Due to the influence of the gravitational field of the upper rock mass, stress concentration occurred in the inner layer of the muddy interlayer, resulting in a significant increase of the sliding thrust of the interlayer and aggravated the tendency of the slope slip.

(3) The large infiltration of rainwater led to the phenomenon of plastic flow extrusion of the slope at the interlayer extrusion. With the further penetration of the tensile fracture in the upper part of the interlayer, the slope had a larger settlement displacement and gradually formed sliding shear deformation along the weak structural plane.

(4) Under the condition of equal rainfall amount, the condition of long-time heavy rain has a greater influence on the stability of the bedding rock slope with weak interlayer than that of short-time rainstorm. According to the test results under long-time heavy rain condition, the instability development forms of this kind of slope were divided into four stages: prechange stage, interlayer extrusion stage, slip-pullfracture stage, and plastic flow-shear failure stage.

\section{Conflicts of Interest}

The authors declare that they have no conflicts of interest.

\section{Acknowledgments}

This work was financially supported by the National Science Foundation of China (51678073 and 51508042) and the Open Fund of Key Laboratory of Special Environment Road Engineering of Hunan Province (Changsha University of Science and Technology), China (kfj140501), and the Research Foundation of Hunan Province (2016SK2023).

\section{References}

[1] S. D. Li, X. Li, J. Wu, and Y. Liu, "Evolution process and pattern of sliding zone in large consequent bedding rock landslide," Chinese Journal of Rock Mechanics and Engineering, vol. 12, pp. 2473-2480, 2007.

[2] J. S. Shu, Q. X. Cai, C. L. Wang, and H.-G. Peng, "Inquire into critical inclination of failure face in rock slope with planar failure," Journal of China University of Mining \& Technology, vol. 4, pp. 437-440, 2006.

[3] S. E. Bedoui, Y. Guglielmi, T. Lebourg, and J.-L. Pérez, "Deepseated failure propagation in a fractured rock slope over 10,000 years: the La Clapiere slope, the south-eastern French Alps," Geomorphology, vol. 105, no. 3-4, pp. 232-238, 2009.
[4] D. Tiranti, D. Rabuffetti, A. Salandin, and M. Tararbra, "Development of a new translational and rotational slides prediction model in Langhe hills (north-western Italy) and its application to the 2011 March landslide event," Landslides, vol. 10, no. 2, pp. 121-138, 2013.

[5] F. Guzzetti, F. Ardizzone, M. Cardinali, M. Galli, P. Reichenbach, and M. Rossi, "Distribution of landslides in the Upper Tiber River basin, central Italy," Geomorphology, vol. 96, no. 1, pp. 105-122, 2008.

[6] H. Y. Fu, L. Zeng, G. Y. Wang et al., "Stability analysis of soft rock slope under rainfall infiltration," Rock and Soil Mechanics, vol. 33, no. 8, pp. 2359-2365, 2012.

[7] L. He, Rock Slope Rainfall Disaster and Support Optimization Research, pp. 1-5, Southwest Jiaotong University, Chengdu, China, 2015.

[8] G. Fan, J. J. Zhang, X. Fu, and H. Tian, "Energy identification method for dynamic failure mode of bedding rock slope with soft strata," Chinese Journal of Geotechnical Engineering, vol. 38, no. 5, pp. 959-966, 2016.

[9] H. Lin, W. W. Zhong, and P. Cao, "Three-dimensional rock slope stability analysis considering the surface load distribution," European Journal of Environmental and Civil Engineering, vol. 20, no. 8, pp. 877-898, 2016.

[10] X. L. Li and K. Zhang, "Characteristics and variation trend of rainfall in Changsha in recent 50 years," Rural Economy and Science-Technology, vol. 26, no. 9, pp. 44-46, 2015.

[11] D. Tang and D. Q. Li, C. B. Zhou and K.-K. Phoon, Slope stability analysis considering antecedent rainfall process," Rock and Soil Mechanics, vol. 34, no. 11, pp. 3239-3248, 2013.

[12] D. Tang, X. H. Qi, S. H. Jiang, and D. Q. Li, "Effect of different antecedent rainfalls and SWCCs on slope stability," Chinese Journal of Rock Mechanics and Engineering, vol. 37, no. 1, pp. 148-155, 2015.

[13] H. Lin and J. Y. Chen, "Back analysis method of homogeneous slope at critical state," KSCE Journal of Civil Engineering, vol. 21, no. 3, pp. 670-675, 2017.

[14] L. Q. Li, S. X. Luo, W. K. Wei et al., "Model tests of rainfall infiltration effect on bedding rock slope with weak interlayer," Chinese Journal of Rock Mechanics and Engineering, vol. 32, no. 9, pp. 1772-1778, 2013.

[15] X. H. Qin, D. S. Liu, Q. H. Song et al., "Infiltration model of bedrock laminar slope under heavy rainfall and its stability analysis," Rock and Soil Mechanics, vol. 37, no. 11, pp. 31563164, 2016.

[16] Z. Li, Y. J. He, H. E. Li, and H. Xu, "Model test on slope landslides under antecedent rainfall," Journal of Hohai University, vol. 44, no. 5, pp. 400-405, 2016.

[17] S. Zeng, Z. C. Li, H. Wei et al., "Stability analysis of red sandstone bedding slope under rainfall infiltration and drywet cycling," Rock and Soil Mechanics, vol. 34, no. 6, pp. 1536-1540, 2013.

[18] S. C. Wu, Analysis of the Sensitivity of the Rock Mass Parameters to the Stability of Slope, pp. 36-87, China University of Geosciences for Master Degree, Wuhan, China, 2012.

[19] Y. C. Ye, Y. W. Shi, Q. H. Wang et al., "Test model research on low strength similar material of Shanghengshan multilayer shale deposit," Rock and Soil Mechanics, vol. 35, no. 2, pp. 114-120, 2014.

[20] H. Su, H. Q. Zhou, S. Wu et al., "Research on similar material of slope construction simulation experiment," Highway Engineering, vol. 41, no. 2, pp. 61-65, 2016.

[21] Y. Wang, W. T. Mao, Z. J. Wang et al., "Similar material study on failure mechanism model test of red bed slope," Subgrage Engineering, vol. 5, pp. 73-77, 2016. 


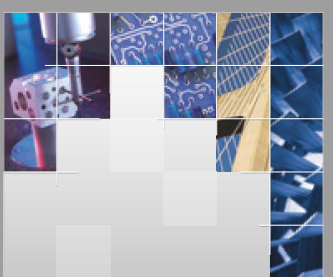

\section{Enfincering}
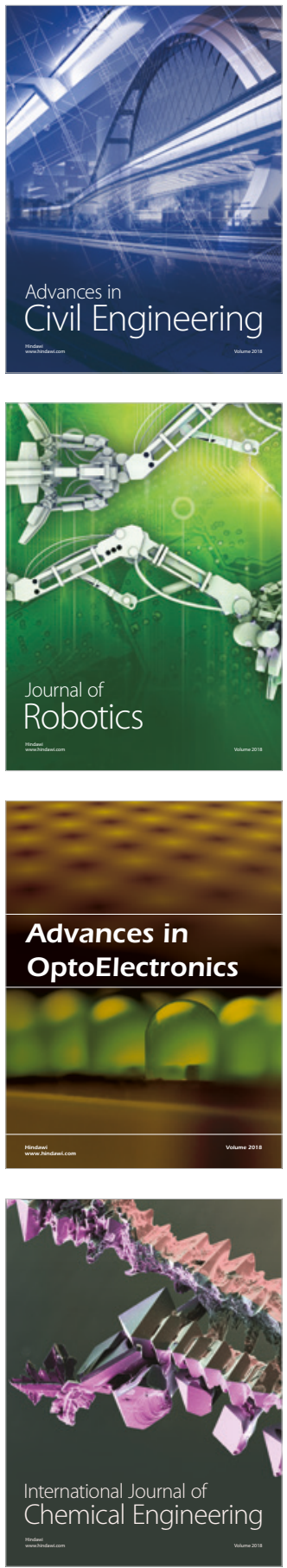

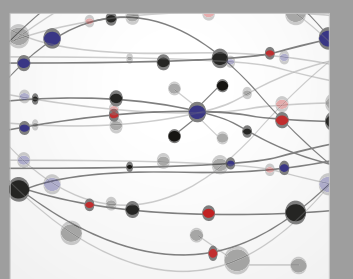

\section{Rotating \\ Machinery}

The Scientific World Journal

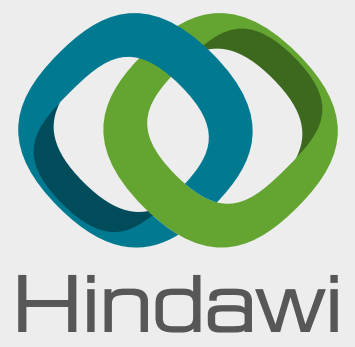

Submit your manuscripts at

www.hindawi.com
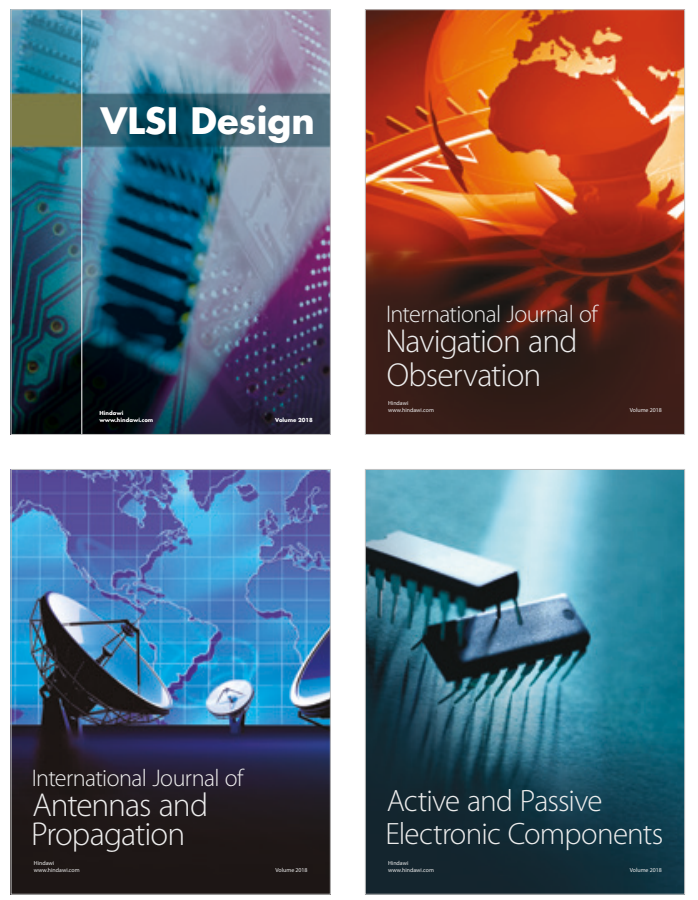
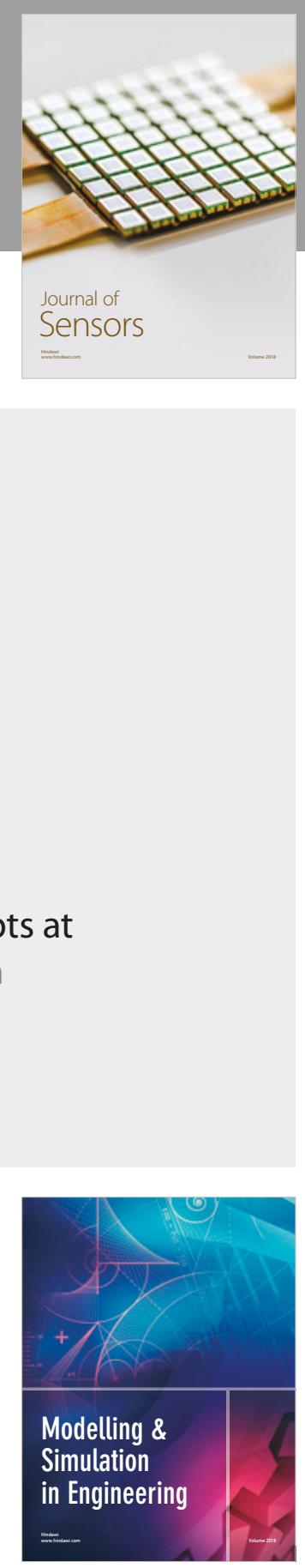

\section{Advances \\ Multimedia}
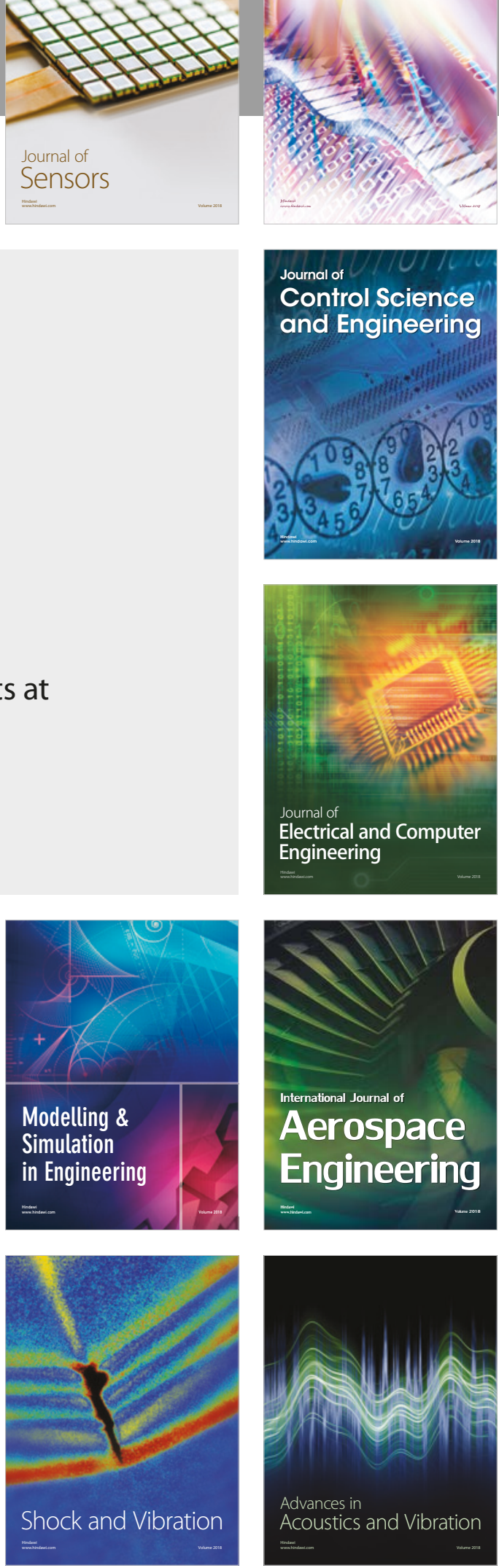